\title{
Quality of Life in Pediatric Patients with Allergic Rhinitis treated at the Medical Clinic of Integrated Education - Unisul
}

\author{
Mariana Dziekanski ${ }^{1}$ Taíse de Freitas Marcelino ${ }^{2}$ \\ ${ }^{1}$ Medical School, Campus Tubarão Ringgold Standard Institution, \\ Universidade do Sul de Santa Catarina - Unisul, Tubarão, SC, Brazil \\ 2 Otorhinolaryngology, Medical School, Unisul, Tubarão, SC, Brazil \\ Int Arch Otorhinolaryngol 2017;21:371-376.
}

\author{
Address for correspondence Mariana Dziekanski, Medical Student, \\ Curso de Medicina, Universidade do Sul de Santa Catarina, Campus \\ Tubarao, Avenida José Acácio Moreira, 787 Bairro Dehon, Tubarao, \\ Santa Catarina 88704-900, Brazil \\ (e-mail: maridzie@gmail.com; marianadzie@hotmail.com).
}

\begin{abstract}
Keywords

- rhinitis

- allergic

- quality of life

- pediatrics

- otolaryngology
\end{abstract}

\section{Introduction}

Allergic rhinitis (AR) is defined as an inflammation of the nasal mucosa mediated by immunoglobulin $\mathrm{E}(\operatorname{IgE})$, which occurs after exposure to allergens. According to the recommendation of the Allergic Rhinitis and Its Impact on Asthma (ARIA) and the World Health Organization (WHO), its classification should take into account the duration and severity of symptoms, as well as quality of life (QoL) aspects. In pediatrics, AR represents a global health problem and, while not posing a risk of death, has a significant impact on the child's life. It is a prevalent pathology in pediatrics, reaching $\sim 30 \%$ of the population, on average $13 \%$ to $21 \%$ of preschoolers, $15 \%$ of schoolchildren, and up to $40 \%$ of adolescents. $^{1-5}$ received

December 5, 2016

accepted

January 6, 2017

published online

March 15, 2017
DOI https://doi.org/

10.1055/s-0037-1599095. ISSN $1809-9777$.
Copyright $(2017$ by Thieme Revinter

Publicações Ltda, Rio de Janeiro, Brazil
License terms

(c) $(1) \$$ 
The AR is a chronic disease, thus it has a negative impact on the child's QoL and, because it is a disease of the upper airways, if not properly controlled, it can predispose rhinosinusitis, otitis media, and hearing loss, with adverse consequences on school cognition. Current studies have evidenced the negative impact of AR on the learning process, cognitive ability, memory, and psychosocial relationships, as well as predisposition to behavioral disorders, such as restlessness, irritability, inattention, and daytime sleepiness. These symptoms may impair the child's concentration and may adversely affect performance in a variety of settings. ${ }^{6-10}$

In childhood it is usually underdiagnosed because the symptoms are nonspecific and attributable to recurrent colds. Its main symptoms are: clear coryza, nasal obstruction, nasal itchiness, ocular itchiness, palatal or pharyngeal itchiness, sneezing, and tearing. This fact is more pronounced in the first years of life, at a time when viral infections are quite frequent. Children with AR are also more likely to present with atopic eczema and asthma, coexisting in 50\% to $60 \%$ of pediatric patients. The diagnosis of AR during childhood is clinical, with emphasis on the family history and description of the child's living environment. Achieving a good medical history is still the best tool. ${ }^{8,11,12}$

The treatment aims to provide guidance on environmental control at home, exercise practice, and drugs to prevent and treat crises. This is a challenge for the professionals involved, mainly due to the importance of the disease in triggering other problems that alter the QoL and health of the child. Studies have shown that the intensity of symptoms does not necessarily correlate with the level of impairment in QoL, since the degree of impairment depends mainly on the individual's own standards of well-being, the perception of the world around him, and treatment expectations. The literature describes that, not only does sleep impairment have an important impact on social life, professional skills, and learning of patients, but the treatment of AR can have a beneficial effect on reducing the limitations from sleep disorders. ${ }^{13-16}$

Therefore, knowing the impact that AR has on individuals' QoL and how the disease affects their physical, mental, and social development may contribute to a better understanding of the disease and how it affects patients' lives. Thus, we defined our research question as: How is the QoL of pediatric patients with AR treated at the Medical Clinic of Integrated Education (MCIE) - Universidade do Sul de Santa Catarina Unisul, Tubarão, SC, Brazil?

\section{Methods}

This is an observational study, with a cross-sectional design performed at the MCIE, located in C block of Unisul. The population of this study was composed of pediatric patients treated at our pediatric clinic from March 2011 to June 2016. The study included children and adolescents between 6 and 16 years old with clinical diagnosis of AR by medical records or those whose parents or guardians responded positive for AR through the International Study of Asthma and Allergies in Childhood (ISAAC) Questionnaire - rhinitis module at the time of the interview.
For the calculation of a convenience sample size, we verified the number of attendances of the year 2015, 80 attendances, with an expected frequency of a $50 \%$ risk factor, $\alpha$ of $5 \%$, with the minimum required sample being 64 patients. The sample in this study involved 69 pediatric patients with AR.

We included pediatric patients 6 to 16 years old with clinical diagnosis of AR, whose parents or guardians signed the Free and Informed Consent Term and literate patients, as well as those with ability to understand the questionnaire, signed the Free and the Informed Assent Term.

We excluded all data from the participants who illegibly answered the questionnaires, as well as those who gave up participating in the study. We also excluded patients with other chronic diseases or comorbidities that could compromise health-related QoL, such as sinusitis or food allergy. We performed the data collection from March to June 2016 through contact with the parents or guardians of the patients and invitation to research participation, followed by the application of the questionnaires as collection instruments.

\section{Sociodemographic and Health Questionnaire}

The authors prepared the questionnaire to evaluate the profile of the interviewed, containing sociodemographic and health data. Among the most important were: gender, age, parents or guardians education, family income, treatment of AR, comorbidities (asthma and eczema), and personal and family smoking, data reported by the patient and/or parents/guardians.

\section{International Study of Asthma and Allergies in Childhood (ISAAC) Questionnaire - Rhinitis Module 1.2} We applied the standard written questionnaire (WQ) of the International Study of Asthma and Allergies in Childhood (ISAAC), ${ }^{17}$ rhinitis module. This instrument was validated in Brazil by Vanna ${ }^{18}$ and is composed of six questions that have as objectives: to identify individuals with or without rhinitis in the sample population (questions 1 and 2); predict, among those who have rhinitis, the possibly atopic (question 3: rhinoconjunctivitis); presence of symptoms month-to-month (question 4), determine the degree of severity (question 5); and assess the presence of a medical diagnosis of rhinitis (question 6). In this research, we used the questionnaire to confirm AR through a positive answer of questions 1 and 6 .

\section{Rhinoconjunctivitis Quality of Life Questionnaire Modified (RQLQm)}

The modified Rhinoconjunctivitis Quality of Life Questionnaire (RQLQm), ${ }^{19}$ validated by Nascimento, ${ }^{9}$ is a diseasespecific questionnaire used to evaluate the QoL of patients with nasal disease and can be applied in the evaluation of patients with AR. It consists of 26 items divided into four domains: symptoms, practical problems, emotions, and activities. The evaluation of each symptom is done through a seven-point feel scale, in which 1 means "I didn't feel discomfort" and 7 means "Disturbed me extremely" (yellow card) or 1 means "I didn't feel discomfort" and 7 means "Disturbed me extremely all the time" (green card). 
We entered the data into Microsoft Office Excel 2007 and analyzed them with the SPSS 20.0 statistical program (IBM Corp., Armonk, U.S.A.). We described the quantitative variables with measures of central tendency and dispersion and qualitative variables in absolute numbers and proportions. As a descriptive study, we did not perform statistical tests because they did not have a comparison group. We used $95 \%$ confidence interval and error $\alpha=5 \%$ for the prevalence rate. Values of $p<0.05$ were considered significant. The study was submitted to the Ethics Committee on Research and approved on $07 / 12 / 2015$, under the number 1,798,284. We followed the guidelines contained in Resolution 466/ 2012 of the National Health Council.

\section{Results}

We applied a total of 207 questionnaires among 69 pediatric patients with clinical diagnosis of AR treated at MCIE/Unisul.

According to the Sociodemographic and Health Questionnaire, among the patients analyzed, boys prevailed, represent-

Table 1 Sociodemographic and health data of pediatric patients with allergic rhinitis in 2016*

\begin{tabular}{|c|c|c|}
\hline Variable & $N=69$ & $\%$ \\
\hline \multicolumn{3}{|l|}{ Gender } \\
\hline Male & 36 & 52.2 \\
\hline Female & 33 & 47.8 \\
\hline \multicolumn{3}{|l|}{ Age } \\
\hline Mean & 10.13 & $\mathrm{SD} \pm 2.844$ \\
\hline \multicolumn{3}{|l|}{ Parent / Guardian Education } \\
\hline 1st grade incomplete & 10 & 14.5 \\
\hline 1st grade complete & 08 & 11.6 \\
\hline 2nd grade incomplete & 27 & 39.1 \\
\hline 2nd grade complete & 13 & 18.8 \\
\hline 3rd grade incomplete & 04 & 5.8 \\
\hline 3rd grade complete & 07 & 10.1 \\
\hline \multicolumn{3}{|l|}{ Income } \\
\hline 1 minimum wage & 05 & 7.2 \\
\hline 2 minimum wages & 42 & 60.9 \\
\hline 3 minimum wages or more & 22 & 31.9 \\
\hline \multicolumn{3}{|l|}{ Treatment } \\
\hline Allergic Rhinitis & 56 & 81.2 \\
\hline \multicolumn{3}{|l|}{ Comorbidities } \\
\hline Asthma & 21 & 30.4 \\
\hline Eczema & 05 & 7.2 \\
\hline \multicolumn{3}{|l|}{ Smoking } \\
\hline Personal & - & - \\
\hline Family & 12 & 17.4 \\
\hline
\end{tabular}

Abbreviation: SD, standard deviation.

*treated at the Medical Clinic of Integrated Education - Universidade do Sul de Santa Catarina, Tubarão, SC, Brazil. ing a little more than half of the studied population, whose mean age was 10 years. Among the parents or guardians education level, the majority stated they had not completed the second grade and the minority stated that they had not completed the third grade. Regarding income, the majority of the respondents declared an income of two minimum wages, almost a third received three minimum wages or more, and only a small portion received one minimum wage. Regarding treatment, the vast majority of respondents stated that they had already had treatment for current or previous AR. Among the comorbidities presented, asthma was present in most of the interviewed, followed by eczema in a small amount. Personal smoking was absent in this study, and family smoking was present in a small part, with a minimum of 5 and a maximum of 20 cigarettes/day ( - Table $\mathbf{1}$ ).

According to the rhinitis module of the ISAAC Questionnaire, 69 respondents (100\%) stated yes in question 1, regarding rhinitis and question 6 , concerning the medical diagnosis of AR. Among them, 43 (62.3\%) answered yes to question 2, which restricted these symptoms to the last 12 months, setting up active rhinitis. Therefore, the 26 (37.7\%) who answered no to this question jumped to question 6 . In question 3 on rhinoconjunctivitis, 18 (41.9\%) reported that the problem was concurrent with ocular symptoms.

Regarding the occurrence of AR symptoms in relation to the months of the year, most of the patients answered that the months of greatest occurrence were between March and July, with May being the month of most involvement and October with the lowest incidence of symptoms (-Table $\mathbf{2}$ ). Regarding the severity of the disease, most patients responded that nasal problems had a little effect on their daily activities and only a small portion reported that they disturbed a lot ( - Table $\mathbf{3}$ ).

In reference to the RQLQm Questionnaire, the subjective evaluation of the severity of the disease perceived by the patient received on average a little more than half of the

Table 2 Occurrence of nasal symptoms in pediatric patients with allergic rhinitis per month in $2016^{*}$

\begin{tabular}{|l|l|l|}
\hline Variable & $\mathbf{n}$ & \% \\
\hline January & 03 & 4.3 \\
\hline February & 09 & 13.0 \\
\hline March & 18 & 26.0 \\
\hline April & 23 & 33.3 \\
\hline May & 26 & 37.6 \\
\hline June & 24 & 34.7 \\
\hline July & 16 & 23.1 \\
\hline August & 07 & 10.1 \\
\hline September & 02 & 2.8 \\
\hline October & 01 & 1.4 \\
\hline November & - & - \\
\hline December & - & - \\
\hline
\end{tabular}

*treated at the Medical Clinic of Integrated Education - Universidade do Sul de Santa Catarina, Tubarão, SC, Brazil. 
Table 3 Interference in daily activities by nasal problems in the last 12 (twelve) months in pediatric patients with allergic rhinitis in $2016^{*}$

\begin{tabular}{|l|l|l|}
\hline Variable & $\mathbf{n}$ & $\%$ \\
\hline A little & 29 & 42.0 \\
\hline Not at all & 26 & 37.7 \\
\hline A moderate amount & 9 & 13.0 \\
\hline A lot & 5 & 7.2 \\
\hline
\end{tabular}

*treated at the Medical Clinic of Integrated Education - Universidade do Sul de Santa Catarina, Tubarão, SC, Brazil.

maximum score, while the QoL scores presented lower mean values within the possible variation. Among the domains, "Symptoms" was the one that received the most points; however, "Emotions" and "Practical Problems" received fewer points, obtaining on average a small amount of possible points. On the other hand, the "Nasal Symptom Score" obtained a much higher score than the others, receiving more than half of the possible points (-Table 4 ).

Regarding the "Nasal Symptom Score," which evaluates the presence and intensity of the symptoms, nasal itchiness predominated. Of the absent symptoms, the predominance was of sneezing, followed by coryza in some patients, and nasal obstruction was singly mentioned. None of the interviewed cited nasal itchiness as absent. Among the mild symptoms, most cited nasal itchiness, followed by nasal obstruction, with slightly smaller and equal values for sneezing and coryza. Among the moderate symptoms, the predominance was nasal obstruction and coryza, followed by nasal itchiness and sneezing, with values very close to each other. Among the severe symptoms, all variables had the same score ( $\mathbf{- T a b l e ~} \mathbf{5}$ ).

Concerning the domains, in "Symptoms" the most prevalent annoyance in general was itchy nose, followed by stuffy nose, and sneezing. Runny nose appeared to be uncomfortable a few times and the symptoms headache and itchy eyes generally bothered less the respondents. Watery eyes, dry throat, fatigue, and postnasal drip were the ones that caused less discomfort, and the itching on the mouth or throat was the symptom that presented the lowest index between them (-Table 6 ).

Table 4 Severity and mean quality of life score for pediatric patients with allergic rhinitis in 2016*

\begin{tabular}{|l|l|l|l|}
\hline Variable & Mean & $95 \% \mathrm{Cl}$ & $\begin{array}{l}\text { Possible } \\
\text { Variation }\end{array}$ \\
\hline Severity & 51.957 & $47.68-56.23$ & $0-100$ \\
\hline $\begin{array}{l}\text { Nasal Symptoms } \\
\text { Score }\end{array}$ & 9.072 & $8.56-9.59$ & $4-16$ \\
\hline Symptoms & 18.405 & $16.52-20.28$ & $11-77$ \\
\hline $\begin{array}{l}\text { Practical } \\
\text { Problems }\end{array}$ & 7.971 & $7.17-8.76$ & $6-42$ \\
\hline Emotions & 8.420 & $7.48-9.35$ & $6-42$ \\
\hline
\end{tabular}

*treated at the Medical Clinic of Integrated Education - Universidade do Sul de Santa Catarina, Tubarão, SC, Brazil.
Table 5 Nasal symptoms score in the last week of pediatric patients with allergic rhinitis in 2016*

\begin{tabular}{|l|l|l|l|l|}
\hline Variable & Absent & Mild & Moderate & Severe \\
\hline Nasal itchy & - & $48(69.6 \%)$ & $20(29.0 \%)$ & $1(1.4 \%)$ \\
\hline $\begin{array}{l}\text { Nasal } \\
\text { obstruction }\end{array}$ & $1(1.4 \%)$ & $46(66.7 \%)$ & $21(30.4 \%)$ & $1(1.4 \%)$ \\
\hline Coryza & $7(10.1 \%)$ & $40(58.0 \%)$ & $21(30.4 \%)$ & $1(1.4 \%)$ \\
\hline Sneezing & $8(11.6 \%)$ & $40(58.0 \%)$ & $20(29.0 \%)$ & $1(1.4 \%)$ \\
\hline
\end{tabular}

*treated at the Medical Clinic of Integrated Education - Universidade do Sul de Santa Catarina, Tubarão, SC, Brazil.

Among the "Practical Problems," to wipe the nose repeatedly was the one that most caused discomfort, followed by to rub the nose repeatedly, having to carry handkerchiefs and having to take medication in smaller proportions. The evaluation domain "Can't eat certain foods" did not bother any of the interviewed in the previous week ( - Table 7 ). In the "Emotions" domain, a small proportion of patients reported being bothered in the previous week by feeling impatient and irritable, followed by anxious, nervous, embarrassed, and angry (- Table 8). Therefore, it is clear that, in general, the QoL of the patients interviewed was evaluated as low, considering the high mean values for severity and QoL scores obtained through the questionnaires applied.

\section{Discussion}

AR is one of the most common diseases in childhood and adolescence, affecting 10 to $40 \%$ of young people worldwide. The evaluation of QoL has attracted the attention of researchers in the field, now considered a key item in the context of clinical research. In daily practice, it can be used to measure the contribution of clinical management to reduce the impact of chronic diseases on the patient's daily life. Its use allows the physician, usually familiar with the physical evaluation of the patient, to approach his/her psychosocial universe and to see it integrally. $9,20,21$

A Swiss study with schoolchildren showed a positive predictive value of $80 \%$ for rhinitis using the rhinitis module of the ISAAC questionnaire. ${ }^{22}$ Results found in other studies were satisfactory in estimating the impact of AR on the QoL of the interviewed through RQLQm. 9,12,14,19

A study in Uberlândia/MG obtained a majority of male participants and mean age of 9.22 years, which corroborates with the data found in this research. Regarding parents/ guardians education, the predominance was of low educational level, differing from this study. ${ }^{5}$ Other studies showed a majority of females, with varying ages. ${ }^{9,10,12,14}$ The low level of socioeconomic status found in most of the studies analyzed is in agreement with the data collected by this study. 5,12,23

In relation to comorbidities, many studies have shown that the percentage of patients who reported presenting asthma and/or eczema associated with AR had higher values than those found by this study, pointing to asthma coexisting in up to $60 \%$ of the cases. ${ }^{2,3,11,16}$ A study of 979 patients in France found an average prevalence of $22.6 \%$ of asthma and $9.6 \%$ of eczema among AR patients, similar 
Table 6 Repercussion of discomfort in the domain "symptoms" in pediatric patients with allergic rhinitis in the previous week in $2016^{*}$

\begin{tabular}{|l|l|l|l|l|l|l|l|}
\hline Variable & Didn't & Some & A little & Moderate & A lot & Great & Extreme \\
\hline Itchy nose & $39.1 \%$ & $31.9 \%$ & $15.9 \%$ & $4.3 \%$ & $7.2 \%$ & $1.4 \%$ & - \\
\hline Stuffy nose & $40.6 \%$ & $27.5 \%$ & $14.5 \%$ & $4.3 \%$ & $7.2 \%$ & $4.3 \%$ & $1.4 \%$ \\
\hline Sneezing & $47.8 \%$ & $30.4 \%$ & $13.0 \%$ & $1.4 \%$ & $4.3 \%$ & $1.4 \%$ & $1.4 \%$ \\
\hline Runny nose & $46.4 \%$ & $24.6 \%$ & $14.5 \%$ & $7.2 \%$ & $7.2 \%$ & - & - \\
\hline Headache & $59.4 \%$ & $24.6 \%$ & $7.2 \%$ & $1.4 \%$ & $4.3 \%$ & $2.9 \%$ & - \\
\hline Itchy eyes & $65.2 \%$ & $27.5 \%$ & $4.3 \%$ & - & $1.4 \%$ & $1.4 \%$ & - \\
\hline $\begin{array}{l}\text { Fatigue/ } \\
\text { Tiredness }\end{array}$ & $68.1 \%$ & $24.6 \%$ & $2.9 \%$ & $1.4 \%$ & $2.9 \%$ & - & - \\
\hline Watery eyes & $71.0 \%$ & $20.3 \%$ & $5.8 \%$ & - & $2.9 \%$ & - & - \\
\hline Dry throat & $79.7 \%$ & $13.0 \%$ & $4.3 \%$ & $1.4 \%$ & - & - & $1.4 \%$ \\
\hline Postnasal drip & $82.6 \%$ & $11.6 \%$ & $2.9 \%$ & $1.4 \%$ & - & - & - \\
\hline $\begin{array}{l}\text { Itching } \\
\text { mouth/throat }\end{array}$ & $84.1 \%$ & $8.7 \%$ & $7.2 \%$ & & & - \\
\hline
\end{tabular}

*treated at the Medical Clinic of Integrated Education - Universidade do Sul de Santa Catarina, Tubarão, SC, Brazil.

Table 7 Repercussion of discomfort in the domain "practical problems" in pediatric patients with allergic rhinitis in the previous week in $2016^{*}$

\begin{tabular}{|l|l|l|l|l|l|l|l|}
\hline Variable & Didn't & Some & A few & Moderate & A lot & Most time & Extreme \\
\hline Wipe nose & $62.3 \%$ & $27.5 \%$ & $5.8 \%$ & - & $2.9 \%$ & $1.4 \%$ & - \\
\hline Rub nose & $66.7 \%$ & $21.7 \%$ & $7.2 \%$ & - & $2.9 \%$ & $1.4 \%$ & - \\
\hline Carry handkerchiefs & $72.5 \%$ & $20.3 \%$ & $7.2 \%$ & - & - & - & - \\
\hline Take medications & $72.5 \%$ & $18.8 \%$ & $5.8 \%$ & $2.9 \%$ & - & - & - \\
\hline Can't eat food & $100 \%$ & - & - & - & - & - & - \\
\hline
\end{tabular}

Source: Prepared by the author, 2016.

*treated at the Medical Clinic of Integrated Education - Universidade do Sul de Santa Catarina, Tubarão, SC, Brazil.

values to those found in the present study. ${ }^{12}$ Concerning smoking, a study performed in Maceió/AL also showed absent personal smoking, but with a higher value of family smoking than presented in this study. ${ }^{10}$

Regarding the rhinitis module of the ISAAC questionnaire, a study in Porto Alegre/RS found that $84.2 \%$ of those interviewed with rhinitis had active rhinitis, in which $36.6 \%$ had rhinoconjunctivitis. Regarding the month-tomonth distribution in which the nasal symptoms occurred in the last year, there was an increasing occurrence from January to July, falling from August to December. Also, it presented interference values of nasal symptoms in daily activities of $32 \%$ never, $51 \%$ little, $12 \%$ moderate, and $4.9 \%$ a lot of interference, values that corroborate with those found in the present study. ${ }^{4}$

Among the analyzed studies that used RQLQm, the average subjective severity score of the disease and quality of life scores were high, indicating that the QoL was considered

Table 8 Repercussion of discomfort in the domain "emotions" in pediatric patients with allergic rhinitis in the previous week in $2016^{*}$

\begin{tabular}{|l|l|l|l|l|l|l|l|}
\hline Variable & Didn't & Some & A little & Moderate & A lot & Great & Extreme \\
\hline Impatient & $68.1 \%$ & $23.2 \%$ & $5.8 \%$ & - & $1.4 \%$ & - & $1.4 \%$ \\
\hline Irritable & $69.6 \%$ & $23.2 \%$ & $4.3 \%$ & - & $2.9 \%$ & - & - \\
\hline Anxious & $71.0 \%$ & $23.2 \%$ & $2.9 \%$ & - & $2.9 \%$ & - & - \\
\hline Nervous & $76.8 \%$ & $15.9 \%$ & $2.9 \%$ & $1.4 \%$ & $1.4 \%$ & - & $1.4 \%$ \\
\hline Embarrassed & $76.8 \%$ & $11.6 \%$ & $10.1 \%$ & - & $1.4 \%$ & - & - \\
\hline Angry & $79.7 \%$ & $13.0 \%$ & $5.8 \%$ & - & $1.4 \%$ & - & - \\
\hline
\end{tabular}

*treated at the Medical Clinic of Integrated Education - Universidade do Sul de Santa Catarina, Tubarão, SC, Brazil. 
moderate to low, confirming the results obtained from this research. ${ }^{9,12,14,19}$ A Brazilian study with adolescents showed that the physical symptoms, mainly the nasal ones, were cited as more annoying than emotional agents. Other situations reported to be uncomfortable included fatigue, headache, nervousness, use of medications, and embarrassing situations due to symptoms. ${ }^{9}$ Other studies documented ARrelated situations that most bothered patients, such as increased thirst and difficulty concentrating, similar results to those found by this research. ${ }^{14,24,25}$

A possible limitation of this study was the small number of patients interviewed and the relatively short period of data collection. Although more than $100 \%$ of the estimated minimum sample has been reached, literature data involve a much larger number of patients, in studies promoted by large groups of researchers.

\section{Conclusion}

The results highlight that the allergic symptoms negatively impact the life of children and adolescents with AR, with a predominance of nasal symptoms, especially nasal itchiness, representing a poor QoL of the participants interviewed.

\section{References}

1 Brożek JL, Bousquet J, Baena-Cagnani CE, et al. Global Allergy and Asthma European Network; Grading of Recommendations Assessment, Development and Evaluation Working Group. Allergic Rhinitis and its Impact on Asthma (ARIA) guidelines: 2010 revision. J Allergy Clin Immunol 2010;126(03):466-476

2 Pawankar R, Bunnag C, Khaltaev N, Bousquet J. Allergic Rhinitis and Its Impact on Asthma in Asia Pacific and the ARIA Update 2008. World Allergy Organ J 2012;5(Suppl 3):S212-S217

3 Campanha S, Freire L, Fontes M. O impacto da asma, da rinite alérgica e da respiração oral na qualidade de vida de crianças e adolescentes. Revista CEFAC 2008;10(04):513-519

4 Luna MdeF, Fisher GB, Luna JR, Silva MG, Almeida PC, Chiesa D. Prevalence of rhinitis among 6 and 7-year old students in Fortaleza. Rev Assoc Med Bras (1992) 2014;60(04):357-364

5 Martins da Silva C, da Silva TO, Morales N, Fernandes K, Pinto R. Quality of life in children and adolescents with allergic rhinitis. Rev Bras Otorrinolaringol (Engl Ed) 2009;75(05):642-649

6 Everhart RS, Kopel SJ, Esteban CA, et al. Allergic rhinitis quality of life in urban children with asthma. Ann Allergy Asthma Immunol 2014;112(04):365-70.e1

7 Pawankar R, Baena-Cagnani CE, Bousquet J, et al. State of world allergy report 2008: allergy and chronic respiratory diseases. World Allergy Organ J 2008;1(6, Suppl)S4-S17

8 Oliveira Filho EA. Tratamento da rinite em crianças. Revista AMRIGS 2010;44(04):108-109

9 Nascimento Silva M, Naspitz C, Solé D. Evaluation of quality of life in children and teenagers with allergic rhinitis: adaptation and validation of the Rhinoconjunctivitis Quality of Life
Questionnaire (RQLQ). Allergol Immunopathol (Madr) 2001; 29(04):111-118

10 Castro TM, Marinho DR, Cavalcante CC. The impact of environmental factors on quality of life and symptoms of children with allergic rhinitis. Rev Bras Otorrinolaringol (Engl Ed) 2013;79(05): 569-574

11 Solé D, Camelo-Nunes IC, Wandalsen GF, Rosário NA, Sarinho EC; Brazilian ISAAC Group. Is allergic rhinitis a trivial disease? Clinics (Sao Paulo) 2011;66(09):1573-1577

12 Bousquet PJ, Demoly P, Devillier P, Mesbah K, Bousquet J. Impact of allergic rhinitis symptoms on quality of life in primary care. Int Arch Allergy Immunol 2013;160(04):393-400

13 Camelo-Nunes I, Solé D. Allergic rhinitis: indicators of quality of life. J Bras Pneumol 2010;36(01):124-133

14 Canonica GW, Mullol J, Pradalier A, Didier A. Patient perceptions of allergic rhinitis and quality of life: findings from a survey conducted in europe and the United States. World Allergy Organ J 2008;1(09):138-144

15 Bousquet PJ, Bachert C, Canonica GW, et al. Uncontrolled allergic rhinitis during treatment and its impact on quality of life: a cluster randomized trial. J Allergy Clin Immunol 2010; 126(03):666-8.e1, 5

16 Mir E, Panjabi C, Shah A. Impact of allergic rhinitis in school going children. Asia Pac Allergy 2012;2(02):93-100

17 Pastorino A. Estudo da prevalência de asma e doenças alérgicas, da sensibilização a aeroalérgenos e da exposição a fatores de risco em escolares de 13-14 anos na região oeste da cidade de São Paulo [thesis]. São Paulo, Brazil: FMUSP; 2005

18 Vanna AT, Yamada E, Arruda LK, Naspitz CK, Solé D. International Study of Asthma and Allergies in Childhood: validation of the rhinitis symptom questionnaire and prevalence of rhinitis in schoolchildren in São Paulo, Brazil. Pediatr Allergy Immunol 2001;12(02):95-101

19 Búrigo Locks R. Qualidade De Vida Em Pacientes Com Rinite: Ensaio Clínico Comparando Uso De Bilastina Versus Loratadina [thesis]. Tubarão, Brazil: UNISUL; 2014

20 Mansi N, D’Agostino G, Scirè AS, et al. Allergic Rhinitis in Children: A Randomized Clinical Trial Targeted at Symptoms. Indian J Otolaryngol Head Neck Surg 2014;66(04):386-393

21 Park CE, Shin SY, Lee KH, Cho JS, Kim SW. The effect of allergic rhinitis on the degree of stress, fatigue and quality of life in OSA patients. Eur Arch Otorhinolaryngol 2012;269(09):2061-2064

22 Braun-Fahrländer C, Wüthrich B, Gassner M, et al; International Study of Asthma and Allergies in Childhood. Validation of a rhinitis symptom questionnaire (ISAAC core questions) in a population of Swiss school children visiting the school health services. SCARPOL-team. Swiss Study on Childhood Allergy and Respiratory Symptom with respect to Air Pollution and Climate. Pediatr Allergy Immunol 1997;8(02):75-82

23 Lages Ribeiro M. Validação do questionário de qualidade de vida e avaliação do bem-estar subjetivo de crianças respiradoras orais [thesis]. Belo Horizonte, Brazil: UFMG; 2012

24 Lu D, Zhao Y, Zheng Y, et al. Evaluation of quality of life questionnaires for adult patients with moderate to severe allergic rhinitis. Am J Otolaryngol 2011;32(06):494-498

25 Valero A, Mullol J, Herdman M, Rosales MJ; Spanish CQ7 Study Group. Measuring outcomes in allergic rhinitis: psychometric characteristics of a Spanish version of the congestion quantifier seven-item test (CQ7). Health Qual Life Outcomes 2011;9(01):14 